\title{
Concerning Anesthetically-Induced Frightening NDEs
}

To the Editor:

Kenneth Ring's article on anesthetically-induced frightening neardeath experiences (NDEs) in the Fall 1996 issue of the Journal raised some important questions. He noted properly that women are more adversely affected than men by nitrous oxide, and that the pattern of rotating devices, aversive noise, meaninglessness, and many void and vortex accounts may indeed be little more than drug effects and not true near-death experiences. In so noting, he asked that specific criteria be agreed upon for what constitutes the real thing.

Ring's request seems reasonable enough. On many occasions I too have encountered reports, especially from women, that match his profile exactly. And my conundrum has always been the same as his: are these really near-death experiences or are they something else, such as drug effects? There are cases in which I would heartily agree that the experience was nothing more than a drug effect, but there are others where I must stand my ground and argue otherwise. The story of Gloria Hipple is a case in point. 
In my book Beyond the Light (1994), I discussed, in a chapter on what I term Unpleasant and/or Hell-Like Experiences, what happened to Hipple in August 1955. After being hospitalized for a miscarriage, she "died" of complications from severe blood loss. The primary content of her experience at death was a horrific vortex that spun at great speeds, with a white skull that attacked her. She fought to get out of the vortex but was forced to deal with the skull. By angrily smashing the skull to bits with her fists, her scenario quickly switched to one of being bathed in a welcoming, warm light. Most notable afterwards was her new-found ability to stand up for herself and fight back, a skill she thought herself incapable of.

No drugs were involved in Hipple's case, yet she remembered a similar encounter during the tonsillectomy she had as a child:

Ether was the sedation used to put me to sleep. I recall being terrified by the mask and the awful smell. I can still taste it as I think about it. As the sedation took hold, there was the vortex, the dizzy spinning sensation, as I was dragged downward into sleep. I screamed, not knowing what was happening to me.

As she compared the two episodes, she recognized that the vortex experienced during surgical anesthesia in childhood was the same as the one she had encountered as an adult, except for the smell and taste. This association underscores what one finds in the medical literature: that certain chemicals, especially ether, can cause vortex or spinning hallucinations. Missing from the medical literature, however, is mention of anything more significant than this imagery. No attention is given to possible aftereffects, beyond chemical side effects. Hipple suffered no side effects from the sedation she was given in 1943, nor any aftereffects from being pulled into the vortex, except for a dislike of ether. But her adult confrontation with the same type of vortex did have aftereffects, the kind associated with the neardeath phenomenon.

Hipple's hellish near-death episode was lengthy, intense, fully involved, and resolved in "heavenly" light. A close examination of Hipple's life reveals the sudden development of unique sensitivities afterward. The pending death of an unborn daughter was revealed to her in an unusually detailed vision. When her husband died in a trucking accident at 4:15 one morning, she was up and prepared for it, and even heard a thump against her trailer home at the exact moment he was killed some distance away. Strange sensations about her sister awakened her from a deep sleep at the exact moment her 
sister died. She claims: "I am more sensitive to people's thoughts and actions than before. I follow hunches that are sometimes quite accurate." Her hellish experience transformed her from being dependent on outer circumstances and material possessions to the realization of greater truths and the power of inner peace. Drug-induced hallucinations do not foster the kind of life shift that happened to this woman, and she is one of many such experiencers.

Similar spinning vortexes and clicking or taunting objects that invade one's personal space at dizzying speeds are not at all uncommon in cases of people who were frightened by what they met on the other side of death. Even full-blown hellish scenarios often center around the swirling of great winds or giant whirlpools. Yet, with the majority of these reports, I have been unable to uncover direct causal links between drugs and imagery, regardless of the gender. The few that do qualify as drug-induced experiences hardly constitute a pattern of universal import.

We all have ideas about near-death experiences, but we need to be careful about drawing hard conclusions from them. The phenomenon does not lend itself to scientific analysis. The more narrow our focus in detailing what constitutes a legitimate case, the more we risk distancing ourselves from the very dynamics that seem to power it.

Richard Maurice Bucke (1901) also searched for criteria with which to judge whether or not a given individual had really undergone an episode of what he termed "cosmic consciousness," and what I call a "brain shift." Although he validated out-of- body experiences as genuine, he labeled any scenario experienced while under the influence of drugs "bastard," even if descriptions matched those of "true" illumination. Bucke claimed that artificially induced episodes were vastly inferior and without the lasting, permanent aftereffects associated with enlightenment.

To offer an example of a "bastard" experience as defined by Bucke, here is a quote he gave from a patient under the influence of chloroform:

I seemed at first in a state of utter blankness; then came flashes of intense light, alternating with blankness and with a keen vision of what was going on in the room round me, but no sensation of touch. I thought that I was near death, when suddenly my soul became aware of God, who was manifestly dealing with me, handling me, so to speak, in an intense personal present reality. I felt Him streaming in like light upon me and heard Him saying in no language, but as hands touch hands and communicate sensations: 'I led thee; I guided thee; you will never sin and weep and wail in 
madness any more; for now you have seen Me.' My whole consciousness seemed brought into one point of absolute conviction; the independence of my mind from my body was proved by the phenomenon of this acute sensibility to spiritual facts, this utter deadness of the senses. Life and death mere names. . . I cannot describe the ecstasy I felt. (Bucke, 1901, p. 380)

Surely this sounds like a genuine experience; but because the individual was under the influence of a drug, Bucke discounted the case.

Bucke considered aftereffects the only final determinant of validity, yet he left in doubt what happened afterward to this patient under the influence of chloroform. Although his focus was the broader genre of consciousness transformations, his findings dovetail with neardeath research, especially my own. And for that reason I am arguing that in any redefinition of what constitutes the various types of neardeath experience, the pattern of psychological and physiological aftereffects must be recognized as an integral part of those criteria.

\section{References}

Atwater, P. M. H. (1994). Beyond the light: What isn't being said about the near-death experience. New York, NY: Birch Lane Press.

Bucke, R. M. (1901). Cosmic consciousness: A study in the evolution of the human mind. New York, NY: Innes and Sons.

Ring, K. (1996). A note on anesthetically-induced frightening "near-death experiences." Journal of Near-Death Studies, 15, 17-23.

P. M. H. Atwater, P. O. Box 7691

Charlottesville, VA 22906-7691 